\title{
The quality of life impact of peripheral versus central vision loss with a focus on glaucoma versus age-related macular degeneration
}

This article was published in the following Dove Press journal:

Clinical Ophthalmology

30 July 2009

Number of times this article has been viewed

\author{
Keith Evans' \\ Simon K Law ${ }^{2}$ \\ John Walt ${ }^{3}$ \\ Patricia Buchholz ${ }^{4}$ \\ Jan Hansen ${ }^{3}$ \\ 'Global Health Outcomes, Wolters \\ Kluwer Health, Chester, United \\ Kingdom; ' Jules Stein Eye Institute, \\ Los Angeles, CA, USA; ${ }^{3} \mathrm{Global}$ \\ Health Outcomes Strategy and \\ Research, Allergan Inc., Irvine, CA, \\ USA; ${ }^{4}$ Health Economics, Pricing, \\ and Reimbursement, Allergan $\mathrm{GmbH}$, \\ Ettlingen, Germany
}

Purpose: It is well accepted that conditions that cause central vision loss (CVL) have a negative impact on functional ability and quality of life (QoL), but the impact of diseases that cause peripheral vision loss (PVL) is less well understood. Focusing on glaucoma and age-related macular degeneration (ARMD), the effects of CVL and PVL on QoL were compared.

Methods: A systematic literature review of publications reporting QoL in patients with CVL or PVL identified 87 publications using four generic (Short-Form Health Survey-36 and -12, EuroQoL EQ-5D and Sickness Impact Profile) and five vision-specific (National Eye Institute Visual Function Questionnaire-51, -39, and -25, Impact of Vision Impairment and Visual Function-14) QoL instruments; 33 and 15 publications reported QoL in ARMD and glaucoma, respectively.

Results: QoL was impaired to a similar extent by diseases associated with PVL and CVL, but different domains were affected. In contrast to ARMD, mental aspects appeared to be affected more than physical aspects in patients with glaucoma.

Conclusions: The differential impact upon QoL might be a function of the pathology of the diseases, for example potential for blindness and better ability to perform physical tasks due to retention of central vision may explain these observations in glaucoma.

Keywords: vision loss, quality of life, glaucoma, age-related macular degeneration, diabetic macular edema, cataracts

\section{Introduction}

Visual impairment is a highly prevalent condition. In the US in 2000, nearly 1 million people over the age of 40 years were estimated to be blind and an additional 2.4 million had low vision. ${ }^{1}$ These numbers are projected to increase by approximately $70 \%$ over the next 12 years as the population ages. ${ }^{1}$

Age-related macular degeneration (ARMD), glaucoma and cataracts are the leading causes of blindness and low vision globally. ${ }^{1,2}$ ARMD and cataracts affect mainly central vision, although cataracts can also affect peripheral vision, while glaucoma has a larger impact on peripheral vision. The standard treatment for cataracts is surgery, which results in restored vision in more than $95 \%$ of patients, with minimal complications. $^{3}$ ARMD and glaucoma, however, are currently incurable. Although there are existing treatments for ARMD and glaucoma, loss of vision associated with these two diseases is usually irreversible.

Vision loss and blindness have a negative impact on functional ability and quality of life (QoL). ${ }^{4,5}$ Patients with reduced QoL place a greater financial burden on healthcare systems and society than those with better QoL. ${ }^{6-10}$ Impairment of QoL
Global Health Outcomes, Wolters Kluwer Health, Chowley Oak Business Park, Chowley Oak Lane, Tattenhall, Chester CH3 9GA, UK

Tel +44 I829 772884

$\mathrm{Fax}+44$ I829 770330

Email keith.evans@wolterskluwer.com 
in central vision loss (CVL) disorders, such as ARMD, is widely acknowledged, ${ }^{11-14}$ however, the impact on QoL of disorders that cause peripheral vision loss (PVL), such as glaucoma, is less well known. The objective of this study was to compare the QoL impact of PVL with that of CVL by reviewing the published literature. Specific focus was given retrospectively to glaucoma and ARMD because they are two key causes of severe PVL and CVL, respectively. In addition, glaucoma and ARMD are the most frequently described diseases in terms of QoL studies in the published literature in this area.

\section{Methods}

A systematic literature search was performed to identify publications that report QoL in patients with PVL and CVL. The Ovid search platform was used to search four databases: BIOSIS Previews, EMBASE, Cochrane Collaboration and MEDLINE. The search was performed on July 13th 2007 and included publications indexed up to this date.

The search employed mapped terms for central vision and peripheral vision in EMBASE and MEDLINE. Search terms were related to vision (including 'central vision', 'peripheral vision', 'visual perception and fields', 'form, space and pattern recognition', 'fovea centralis', 'eye movements'), vision tests and disorders ('visual acuity', 'macular degeneration', 'choroidal neovascularization'), and 'quality of life'. The names of specific QoL instruments were not included as search terms, in order to capture all publications related to QoL in vision. The electronic search was supplemented by manual searching of the reference lists in each article to identify other relevant papers (eg, publications not indexed in the databases searched).

The search results were limited to publications that included one of the vision keywords and 'quality of life' and that used a generic or vision-specific QoL instrument; QoL instruments had to have reported results for more than one type of vision loss to allow comparison between PVL and CVL disorders. Disease-specific QoL instruments were excluded because they do not enable comparison between vision disorders.

The possibility of combining some, or all, of the results in the form of a meta-analysis was explored where several publications for a specific disorder according to a specific instrument were identified. However, given the high level of heterogeneity observed in terms of study population and design, it was decided not to conduct such an analysis. The weighted mean score was calculated by multiplying the average QoL score from each study by the number of patients in each study. The sum of these values was then calculated and divided by the total number of patients in all of the studies, to give the weighted mean average. The corresponding standard deviations (SD) were calculated by taking the square root of the variance from the weighted mean scores. This approach allowed comparisons between disorders without requiring results to be reported for each individual publication.

\section{Results}

A total of 87 unique publications were identified from the literature search. Four generic and five vision-specific QoL instruments reported the impact of vision loss on QoL (Table 1). Generic QoL instruments were Short-Form Health Survey (SF)-36, and -12, EuroQoL EQ-5D and Sickness Impact Profile (SIP). ${ }^{15-21}$ Vision-specific QoL instruments were National Eye Institute Visual Function Questionnaire (NEI-VFQ)-51, -39, and -25, Impact of Vision Impairment (IVI) and Visual Function (VF)-14. ${ }^{22-25}$

The 87 publications were broadly categorized according to the main type of vision loss (peripheral or central) caused by the disease reported. Because many disorders of the eye are difficult to differentiate as affecting peripheral rather than central vision, or vice-versa, publications that were considered to be more strongly associated with PVL or CVL only are reported. Although choroideremia, retinitis pigmentosa and Usher syndrome were considered to be PVL disorders, no publications meeting criteria for inclusion in the study were identified that reported QoL in these disorders. Therefore, glaucoma publications accounted for all of those that could be classified as relating to QoL in PVL.

There were more publications examining QoL in patients with ARMD than any other vision disorder (33 publications; $38 \%$ ). Because glaucoma accounted for all the publications of QoL in PVL, and ARMD for the majority of publications in CVL, direct comparisons between the two disorders were made. Overall, a total of 45 publications reported QoL in glaucoma $(n=12)$, ARMD $(n=30)$, or both $(n=3)$. The breakdown of the publications identified as those reporting QoL in glaucoma and ARMD, by QoL instrument, is shown in Table 2.

The QoL impact of vision disorders is described for each instrument in the following two sections. Results comparing glaucoma with ARMD are reported first, followed by results comparing glaucoma with CVL disorders other than ARMD. If the study in question was an interventional study, then pre-intervention scores were used. 


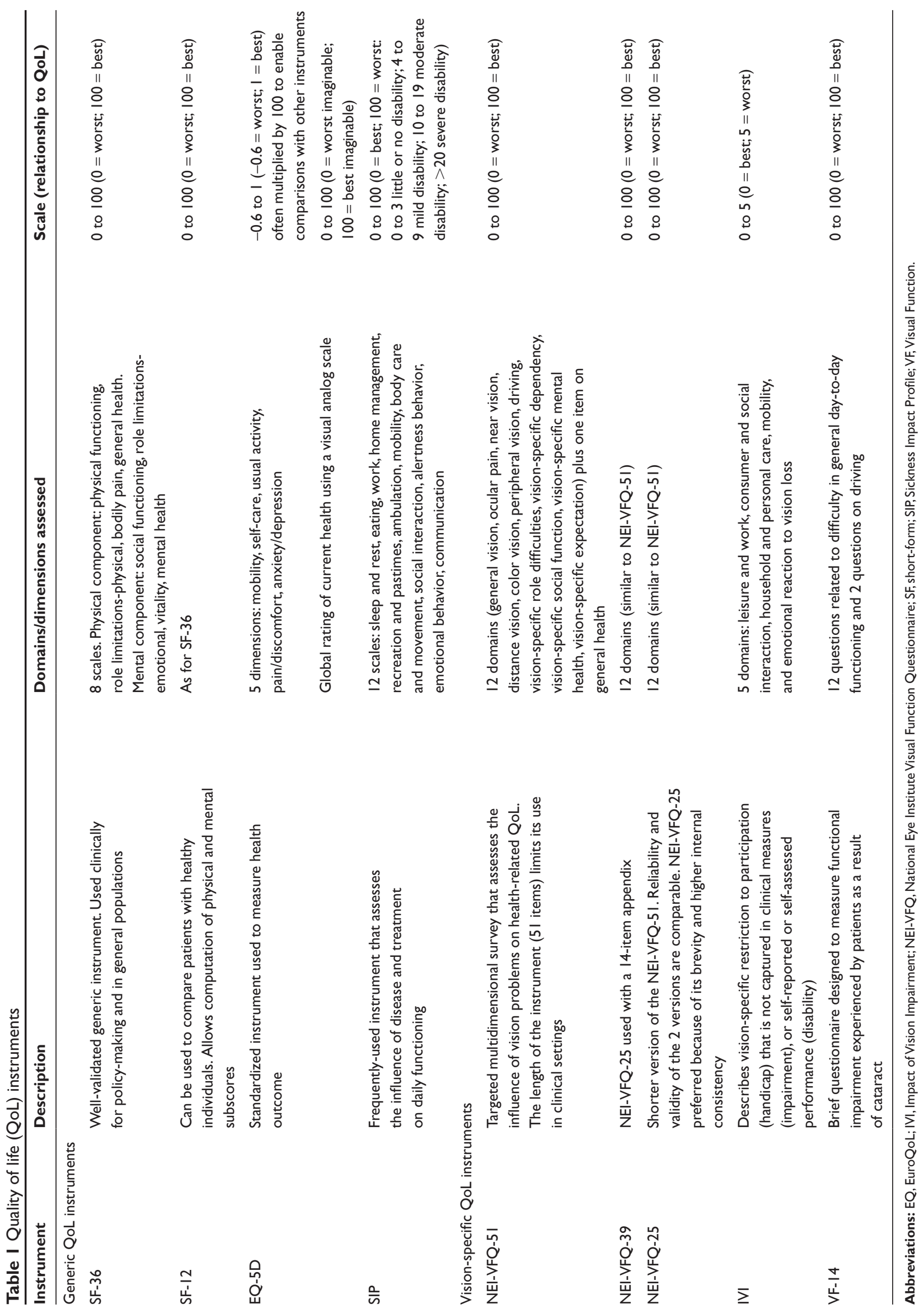




\section{Generic quality of life instruments}

\section{Short-Form Health Survey 36}

Two publications reported QoL in glaucoma (both reported results from the same single study $)^{12,13}$ and five reported QoL in ARMD. ${ }^{14,26-29}$

The two diseases had some similarities and some differences in the QoL domains on which they had an impact. The domains impacted most by glaucoma and ARMD were 'vitality', 'general health', 'role limitations caused by physical problems' and 'role limitations caused by emotional problems' (Table 3). Glaucoma appeared to have a greater impact on 'vitality', 'mental health', 'bodily pain' and 'social functioning' than ARMD. ARMD had a greater impact on 'physical function', 'general health', 'role limitations caused by physical problems' and 'role limitations caused by emotional problems' than glaucoma. Thus, whereas ARMD has a greater impact on the physical component of SF-36 compared with glaucoma, glaucoma has a greater impact on the mental component compared with ARMD.

In diseases other than ARMD that are associated with CVL (cataracts, ${ }^{30-32}$ subfoveal choroidal neovascularization [SCNV], ${ }^{33}$ macular holes ${ }^{34}$ and keratoconus ${ }^{35}$ ), 'role limitations caused by physical problems' and 'general health' (both part of the physical component of SF-36) were affected the most (weighted mean scores were 55-70 and 63-75, respectively).

One publication, the Ocular Hypertension Treatment Study, ${ }^{36}$ reported QoL using SF-36 in patients with ocular hypertension at moderate risk of developing primary openangle glaucoma. This study excluded patients with visual field loss and was therefore not included in our analysis of PVL disorders. However, patients' QoL was affected by their condition. 'Vitality' (part of the mental component of SF-36) was the domain affected most, with a score of 69 (SD: 18).

\section{Short-Form Health Survey 12}

No publications were identified that reported the use of SF-12 in glaucoma or any other PVL disorder. Four publications measured QoL in patients with ARMD using SF-12.37-40 As with SF-36, CVL disorders, including ARMD and cataracts, had a greater impact on the physical component than the mental component of the SF-12 QoL questionnaire; ARMD weighted mean scores were 39.6 (SD: 3.6 ) vs 48.3 (SD: 0.6), respectively. ${ }^{37-41}$

\section{EuroQoL EQ-5D}

One publication reported QoL in glaucoma according to the EQ-5D questionnaire ${ }^{42}$ and there were no publications for
ARMD. Patients with glaucoma exhibited a similar degree of QoL impairment to those with cataracts (the only CVL disease studied using EQ-5D); ${ }^{43,44}$ mean scores were 0.80 (SD: 0.23) and 0.76 (SD: 0.03), respectively. ${ }^{42-44}$

\section{Sickness Impact Profile}

Two publications reported SIP use in glaucoma ${ }^{45,46}$ but no publications used SIP in ARMD. In glaucoma, the psychosocial domain was affected slightly more than the physical domain (scores 3.8 and 3.2, respectively). ${ }^{45,46}$ SIP total scores were slightly higher (QoL was worse) in patients with cataracts than in those with glaucoma (7.5-12.0 vs 3.4-5.2).45-48 The cataract publications reported total scores only, therefore the effect on individual domains could not be analyzed. . $^{47,48}$

\section{Vision-specific quality of life instruments}

National Eye Institute Visual Function Questionnaire-5 I

Three publications reported QoL in glaucoma ${ }^{11-13}$ and two in $\mathrm{ARMD}^{11,14}$ (one publication reported on both glaucoma and ARMD ${ }^{11}$ ) according to NEI-VFQ-51.

Glaucoma and ARMD had some similarities and differences in the domains on which they had an impact (Table 4). The domains affected most by glaucoma were 'expectations', 'general health', 'general vision' and 'peripheral vision', with reported weighted mean scores of 48.3 (SD: 0.2), 67.3 (SD: 1.2), 66.3 (SD: 2.7) and

Table 2 Glaucoma and age-related macular degeneration (ARMD) publications by quality of life instrument

\begin{tabular}{lll}
\hline Instrument & $\begin{array}{l}\text { Glaucoma } \\
\text { publications (n) }\end{array}$ & $\begin{array}{l}\text { ARMD } \\
\text { publications (n) }\end{array}$ \\
\hline SF-36 & 2 & 5 \\
SF-12 & 0 & 4 \\
EQ-5D & 1 & 0 \\
SIP & 2 & 0 \\
NEI-VFQ-5I & $3^{\mathrm{a}}$ & $2^{\mathrm{a}}$ \\
NEI-VFQ-39 & $1^{\mathrm{a}}$ & 3 \\
NEI-VFQ-25 & $8^{\mathrm{b}}$ & $9^{\mathrm{b}}$ \\
IVI & $1^{\mathrm{c}}$ & $1^{\mathrm{c}}$ \\
VF-14 & $1^{\mathrm{c}}$ & 9 \\
Total & $19^{\mathrm{d}}$ & 33 \\
\hline
\end{tabular}

aOne publication reported both glaucoma and ARMD using NEI-VFQ-5I." bone publication reported both glaucoma and ARMD using NEI-VFQ-25. ${ }^{61}$ cOne publication reported both glaucoma and ARMD using IVI. ${ }^{76}$

${ }^{\mathrm{d}}$ Among the glaucoma publications, three publications reported more than one instrument:SF-36 and NEI-VFQ-5I; ${ }^{12}$ SF-36, NEI-VFQ-5I andVF- I4; ${ }^{13}$ and NEI-VFQ-39 and $-25 .^{51}$ Each incidence is shown against the relevant instrument, therefore the number shown here is 19 not 15 , the number of unique publications.

Abbreviations: EQ, EuroQoL; IVI, Impact of Vision Impairment; NEI-VFQ, National Eye Institute Visual Function Questionnaire; SF, short-form; SIP, Sickness Impact Profile; VF, Visual Function. 
71.8 (SD: 3.1), respectively. ${ }^{11-13}$ ARMD had the greatest effect on 'expectations', 'near activities', 'general vision', 'driving' and 'distance activities' (weighted mean scores 40.6 [SD: 1.8], 47.5 [SD: 8.4], 49.0 [SD: 5.7], 50.3 [SD: 14.3] and 52.1 [SD: 12.2$]$, respectively). ${ }^{11}$

While there were no publications reporting QoL in PVL using NEI-VFQ-51 other than in glaucoma, several publications reported QoL in CVL associated with cataracts, ${ }^{11}$ optic neuritis ${ }^{49}$ and diabetic macular edema. ${ }^{50}$ As was the case with ARMD, the domain most affected by CVL in these diseases was 'expectations' (scores 47-66). ${ }^{11,49,50}$ The domains of 'general health' and 'general vision' were also affected in patients with these disorders (scores 57-72 and 60-79, respectively). ${ }^{11,49,50}$

\section{National Eye Institute Visual Function Questionnaire-39 and -25}

The NEI-VFQ-39 was used in one publication for glaucoma ${ }^{51}$ and three publications for ARMD ${ }^{52-54}$ the numbers of publications using NEI-VFQ-25 were $8^{51,55-61}$ and 9,37,38,61-67 respectively; one NEI-VFQ-25 publication reported QoL results in both glaucoma and ARMD. ${ }^{6}$

'General health', 'mental health' and 'general vision' were the domains affected most by glaucoma according to NEI-VFQ-39, with scores of 54.2 (SD: 1.0), 57.8 (SD: 3.9) and 62.6 (SD: 2.0), respectively. ${ }^{51}$ 'General health', 'general vision' and 'driving' were affected most in ARMD (weighted mean scores were 72.0 [SD: 0.2], 74.1 [SD: 4.0] and 74.7[SD: 5.0]). In both disorders, 'social functioning' was affected the least (weighted mean score 84.8 [SD: 1.0] vs 94.2 [SD: 1.9] for glaucoma vs ARMD). This instrument showed that, in general, QoL was affected more severely by glaucoma than by ARMD. However, interpretation of the results for ARMD using NEI-VFQ-39 may be skewed by the weighting given to one large study ${ }^{53}$ which reported higher scores than most of the other smaller studies.

Similar patterns were observed in publications reporting the use of NEI-VFQ-25 (Table 5). 'General health' and 'general vision' were affected most in glaucoma, with weighted mean scores of 47.6 (SD: 7.2) and 68.2 (SD: 7.9). 'Driving', 'general health', 'general vision' and 'near activities' were affected most in patients with ARMD (weighted mean scores: 53.7 [SD: 38.2], 60.6 [SD: 9.0], 61.4 [SD: 21.4] and 62.3 [SD: 27.8]). According to weighted mean scores, glaucoma appeared to have a greater impact on QoL than ARMD although, again, the data may be skewed by one large study in $\mathrm{ARMD}^{65}$ that reported higher scores than other studies. Indeed, in the publication that reported results for both diseases, ARMD appeared to have a greater impact on QoL than glaucoma: ${ }^{61}$ 'general health', 'driving', 'general vision' and 'mental health' (scores of 43.6 [SD: 19.11], 55.3 [SD: 49.9], 62.7 [SD: 19.11] and 68.8 [SD: 24.1], respectively) were significantly affected in glaucoma $(n=69)$ compared with the reference group. In ARMD $(n=78)$, all domains apart from 'peripheral vision', 'color vision' and 'ocular pain' were significantly affected compared with the reference group; the domains affected most were 'driving', 'near activities', 'distance activities', 'mental health', 'role difficulties', 'general vision' and 'general health' (scores of 12.8 [SD: 45.9], 38.6 [SD: 27.4], 40.0 [SD: 28.3], 37.1 [SD: 27.4], 38.4 [SD: 28.3], 41.2 [SD: 20.3] and 45.7 [SD: 20.3], respectively).

The NEI-VFQ-39 and -25 data were similar to those from the NEI-VFQ-51 instrument for diseases associated with CVL other than ARMD (NEI-VFQ-39: cataracts $^{41}$ and SCNV; ${ }^{68-70}$ NEI-VFQ-25: cataracts, ${ }^{61}$ central retinal vein occlusion, ${ }^{71}$ macular holes, ${ }^{34,72}$ optic neuritis ${ }^{73}$ and keratoconus $)^{74,75}$. According to the NEI-VFQ-39 and -25 questionnaires, the QoL impact of non-ARMD CVL disorders followed a similar pattern to that seen for ARMD. 'General vision', 'driving' and 'near activities' were affected most in non-ARMD CVL disorders according to NEI-VFQ-39 (weighted mean scores of 53.2-59.5, 44.3-58.8 and 56.6-65.4); 'general vision', 'driving' and 'general health' were affected the most according to NEI-VFQ-25 (scores 54.1-87.6, 46.0-91.4 and 46.9-83.0). 'Expectations' was the domain most affected in non-ARMD CVL according to NEI-VFQ-51; however, this domain is not included in the NEI-VFQ-39 and -25 questionnaires.

Table 3 Short-form-36 scores for glaucoma ${ }^{12,13}$ and age-related macular degeneration (ARMD) $)^{14,26-29}$

\begin{tabular}{lll}
\hline Domain & $\begin{array}{l}\text { Glaucoma } \\
\text { Mean (SD) }\end{array}$ & $\begin{array}{l}\text { ARMD }^{\mathrm{a}} \\
\text { Mean (SD) }^{\mathrm{a}}\end{array}$ \\
\hline Bodily pain & $72.7(25.4)$ & $75.5(6.0)$ \\
General health & $69.7(21.4)$ & $64.5(6.5)$ \\
Mental health & $72.9(19.7)$ & $74.7(3.3)$ \\
Physical function & $70.6(28.6)$ & $68.2(17.0)$ \\
Role limitation & $66.4(40.3)$ & $55.1(25.4)$ \\
by physical problems & & \\
Role limitation & $69.8(39.9)$ & $65.7(30.0)$ \\
by emotional problems & & $87.3(6.5)$ \\
Social functioning & $80.9(23.4)$ & $60.2(3.2)$ \\
Vitality & $57.8(18.4)$ & \\
\hline
\end{tabular}

${ }^{a}$ Weighted average across studies. 


\section{Impact of Vision Impairment}

One publication reported the use of the IVI questionnaire in patients with glaucoma or ARMD. ${ }^{76}$ Glaucoma affected QoL to a greater extent than ARMD in all domains except for 'social interaction' (scores were 1.93 [SD: 0.98] vs 1.63 [SD: 0.92], 2.38 [SD: 1.12] vs 1.77 [SD: 1.04], 1.77 [SD: 1.04 ] vs 1.50 [SD: 0.61 ], 1.18 [SD: 0.49 ] vs 0.92 [SD: 0.34 ], and 2.79 [SD: 1.32] vs 2.87 [SD: 0.76] for 'emotional reaction to vision loss', 'leisure', 'mobility', 'household' and 'social interaction' domains, respectively) (Table 6). There were no publications reporting QoL in vision disorders other than glaucoma or ARMD using the IVI questionnaire.

\section{Visual Function-14}

The QoL in glaucoma was investigated in one publication ${ }^{13}$ and in ARMD in nine publications ${ }^{14,26,28,77-82}$ using VF-14. The weighted mean values calculated for the ARMD scores were slightly lower than those for glaucoma (score: 69.7 [SD: 14.6] vs 79.1 [SD: 21.8]), although it is important to consider the differences in sample size: a small sample of patients with glaucoma $(n=147)$ compared with ARMD $(n=1307)$.

The only other vision disorder that was identified as having been studied using VF-14 was cataracts, ${ }^{47,48,66,79,83-89}$ for which the weighted mean score was similar to glaucoma and ARMD (score: 74.6 [SD: 7.9]).

\section{Discussion}

Our systematic literature search has shown that diseases associated with PVL and CVL have a negative impact on QoL. Reviewing results from both vision-specific and generic QoL instruments has allowed us to investigate patients' perceptions of visual function, in addition to the influence of their visual disability on more general aspects of QoL, such as emotional well being and social functioning.

\section{Generic quality of life instruments} Glaucoma vs ARMD

A relatively consistent finding with generic QoL instruments was that glaucoma and ARMD appeared to have an impact upon different QoL domains, although a lack of data prohibited comparisons between the two diseases by SF-12 (no glaucoma publications), EQ-5D and SIP (no ARMD publications) results. Overall, in glaucoma, mental components were affected to a greater degree than physical components, whereas the opposite was true for ARMD. In most QoL domains of the SF-36, however, the difference between the impact of the two diseases was slight and unlikely to be clinically significant. The largest differences in SF-36 scores occurred in the 'role limitations caused by physical problems', 'general health' and 'social functioning' (scores were 11.3 points lower for ARMD vs glaucoma, 5.2 points lower for ARMD vs glaucoma, and 6.4 points lower for glaucoma vs ARMD, respectively). All other domains had a difference of four points or less. A possible explanation for this lack of difference between diseases may be because the SF-36 (and therefore the SF-12, which is based on the SF-36 instrument), by design, does not adequately measure functional visual impairment in glaucoma. ${ }^{90,91}$ It is also difficult to draw strong conclusions from the SF-36 data because this instrument was used in only one study (two publications) in glaucoma.

\section{Glaucoma vs non-ARMD CVL disorders}

Wider comparison between diseases affecting central and peripheral vision was not possible as our search found no suitable QoL studies for PVL diseases other than glaucoma. However, SF-36 and SF-12 data supported the greater impact of CVL on physical components than mental components. According to the SF-36, 'role limitations caused by physical problems' and 'general health' were the domains affected the most in patients with the CVL disorders cataracts, SCNV, macular holes and keratoconus.

Other than ARMD, cataract was the most frequentlyreported CVL disorder in terms of QoL publications. Similar results were seen for cataracts with the SF-12 as were seen

Table 4 Effects of glaucoma and age-related macular degeneration (ARMD) on quality of life using the National Eye Institute Visual Function Questionnaire (NEI-VFQ)-5I instrument ${ }^{11-14}$

\begin{tabular}{|c|c|c|}
\hline & Glaucoma & ARMD \\
\hline & $\begin{array}{l}\text { Weighted } \\
\text { mean (SD) }\end{array}$ & $\begin{array}{l}\text { Weighted } \\
\text { mean (SD) }\end{array}$ \\
\hline $\mathrm{N}$ & 225 & 193 \\
\hline General health & $67.3(1.2)$ & $62.6(8.3)$ \\
\hline General vision & $66.3(2.7)$ & $49.0(5.7)$ \\
\hline Ocular pain & $81.7(5.3)$ & $91.5(5.1)$ \\
\hline Near activities & $75.6(3.9)$ & $47.5(8.4)$ \\
\hline Distance activities & $76.3(4.9)$ & $52.1(12.2)$ \\
\hline Social functioning & $86.8(3.0)$ & $71.3(7.5)$ \\
\hline Mental health & $72.6(6.1)$ & $64.3(1.4)$ \\
\hline Expectations & $48.3(0.2)$ & $40.6(1.8)$ \\
\hline Role difficulties & $79.2(5.7)$ & $56.9(8.0)$ \\
\hline Dependency & $85.9(5.2)$ & $65.2(10.0)$ \\
\hline Driving & $75.0(5.1)$ & $50.3(14.3)$ \\
\hline Color vision & $89.6(2.5)$ & $74.1(12.3)$ \\
\hline Peripheral vision & $71.8(3.1)$ & $59.8(19.4)$ \\
\hline
\end{tabular}


with the SF-36. Results using EQ-5D showed that the overall levels of impairment suffered by patients with glaucoma was very similar to patients with cataracts, whereas SIP suggested that QoL was worse in the latter group. For glaucoma, the psychological domain was affected slightly more than the physical domain, with a small and probably clinically irrelevant difference of 0.6 points. However, because only SIP total scores were available for patients with cataracts, there was no opportunity to assess the potential differential impact on the domains of this instrument caused by the two conditions.

Overall, the results from generic instruments showed a difference in the types of aspects of QoL that are affected by glaucoma compared with ARMD; mental more than physical in glaucoma, and vice-versa for ARMD. This may be explained by the differences in the pathology of the diseases. Glaucoma may have less of an inhibitory effect on patients' ability to perform physical day-to-day tasks because their central vision is not affected substantially, but patients may worry about the future impact of their disease on their vision (potential for blindness); ARMD patients, however, may be less able to perform the physical tasks than patients with glaucoma, because of CVL. Vitality and general health were affected substantially in both diseases, indicating that patients have reduced energy levels and perceive that their personal health is poor and likely to get worse.

\section{Vision-specific quality of life instruments} Glaucoma vs ARMD

Results using vision-specific QoL instruments also showed some similarities and differences between glaucoma and ARMD. Across the three NEI-VFQ instruments, 'expectations', 'general health', 'general vision' and, as expected, 'peripheral vision' were affected most in glaucoma, while 'expectations', 'near activities', 'general vision' and 'driving' were affected the most in ARMD. It is interesting that 'expectations' is the domain affected most in both diseases. Although patients diagnosed with glaucoma or ARMD often already have some knowledge about their disease before being invited to participate in a QoL study, this knowledge may not be accurate and lead to low expectations. Ultimately, a lack of patient education about glaucoma and ARMD may be a key factor in the low expectation. For example, although many patients are aware of the lack of an effective treatment for restoring vision loss, most are unaware that surgical procedures are available for glaucoma. Most patients think that having glaucoma or ARMD will eventually lead to blindness. However, the majority of patients with glaucoma and ARMD continue to have functional vision throughout their lifetimes. Nevertheless, even a remote chance of blindness is a huge burden to the patient because of the importance of visual function, and because of the chronic nature of the disease. Patients should be educated about the potential benefits of early diagnosis and appropriate management of glaucoma or ARMD in reducing the chance of severe vision loss and blindness.

The publications we identified appeared to show that QoL is worse in ARMD than in glaucoma; however, only one VF-14 study in glaucoma (147 patients) was identified compared with nine in ARMD (1307 patients), limiting our interpretation of these findings. Similarly, only one study reported IVI data for glaucoma and ARMD; thus, the finding that glaucoma was associated with slightly worse QoL than ARMD in all domains apart from 'social interaction' and that, contrary to the results from other instruments, 'social interaction' was affected most in both diseases, cannot be generalized.

\section{Non-ARMD CVL disorders}

No suitable QoL studies for PVL diseases other than glaucoma were found that used vision-specific QoL instruments. Studies of non-ARMD CVL disorders included optic neuritis and diabetic macular edema, but the majority focused on cataracts.

These studies confirm a significant impact on the 'expectations', 'general vision' and 'general health' domains of NEI-VFQ in patients with CVL disorders. For cataracts specifically, 'expectations', 'general vision', 'driving', 'near activities' and 'general health' were affected the most according to vision-specific QoL instruments, which was consistent with the physical limitations caused by cataracts and patients' curative expectations of cataract surgical procedures.

The finding that 'general health' was affected negatively in patients with diabetic macular edema or optic neuritis was expected; however, the large impact of cataracts on this domain was more surprising and poses the question of whether this is due to the cataract itself or to poor health associated with older age. One publication explored the relationship between visual acuity impairment and eye disease on NEI-VFQ-25 scores in Hispanic adults aged $>40$ years. ${ }^{92}$ After adjusting for visual acuity, the negative effect of cataracts on QoL was no longer significant in any NEI-VFQ-25 domain except 'driving', suggesting that loss of vision could be responsible for the majority of the QoL deficits in this patient population..$^{92}$ This publication was not included in our study because 
changes in scale rather than absolute scores only were reported, preventing direct comparison with results reported in other publications.

Overall, the results from the vision-specific QoL instruments appear to relate more directly to the type of vision loss associated with each disease than results using generic QoL instruments: glaucoma affected peripheral vision whereas ARMD had more of an impact on driving and near and distance activities.

\section{Recent studies}

Among articles published since we conducted our systematic review, one publication reported the use of SF-12 and VF-14 in patients with visual disorders, including glaucoma and ARMD.$^{90}$ In ARMD, but not glaucoma, a decrease in visual impairment was correlated with reduced QoL according to both instruments. ${ }^{90}$ However, the authors acknowledge that the usefulness of the SF-12 (as a derivative of the SF-36) and the VF-14 for adequately capturing functional visual impairment in glaucoma is limited. The VF-14 lacks the ability to measure visual field defect and color vision, which are important indicators in glaucoma. ${ }^{91}$

The NEI-VFQ-25 was used to assess the relationship between depression and vision-related QoL in patients with PVL caused by retinitis pigmentosa, and demonstrated that patients with depression and PVL had poorer vision-related outcomes. ${ }^{93}$ Patients in this study had lower QoL than the glaucoma group in our review on all subscales bar ocular pain (RP [non-depressed patients only]: 76.8 vs glaucoma 75.1) and had lower QoL scores on all subscales than those with ARMD.

Studies in patients with homonymous visual field defects (HVFDs) also showed that they had lower NEI-VFQ-25 scores compared with healthy individuals. ${ }^{94}$ In general, patients with HVFDs had a better QoL on the subscales, but had a lower QoL with regard to general health (44.7), driving (32.6) and peripheral vision (69.7) compared with patients identified in this review with either glaucoma or ARMD. The latter two results are consistent with expectations, since patients with HVFDs are known to find any activity requiring peripheral vision to be highly problematic. They also had slightly lower QoL on the general vision subscale than patients with glaucoma (65.6 vs 68.2).

The NEI-VFQ-39 has also been used to asses visionrelated QoL in cerebrally damaged patients undergoing vision restoration training, and showed that scores increased in response to treatment. ${ }^{95}$ These patients had a poorer QoL on all subscales when compared with the ARMD patients reviewed in this study using the same instrument, but had better QoL than glaucoma patients on four subscales: ocular pain, distance vision, mental health and color vision. However, as the author notes, unless the differences between groups are $>10$ points then the differences are not perceived to be clinically meaningful. Using this definition, the differences between brain-injured patients and ARMD patients are clinically meaningful on all subscales, with the exception of ocular pain and color vision, and the differences compared with glaucoma patients are clinically meaningful on five subscales (ocular pain, role difficulties, driving, color vision and peripheral vision).

Another study using the NEI-VFQ-39 found that visual field loss and visual acuity correlated significantly with vision-related QoL (assessed by NEI-VFQ) but not with health-related QoL (assessed by SF-36) in brain-injured patients. ${ }^{96}$ Comparing the results of this study with those found in our review, we found that brain-injured patients had lower QoL scores on all subscales compared with ARMD patients, and these were clinically meaningful in all cases, with the exception of ocular pain. Compared with glaucoma patients, scores were lower on all subscales, with the exception of ocular pain, mental health and color vision;

Table 5 Effect of glaucoma and age-related macular degeneration (ARMD) assessed using the National Eye Institute Visual Function Questionnaire (NEI-VFQ)-25 instrument ${ }^{37,38,51,55-67}$

\begin{tabular}{|c|c|c|}
\hline & Glaucoma & ARMD \\
\hline & $\begin{array}{l}\text { Weighted } \\
\text { mean (SD) }\end{array}$ & $\begin{array}{l}\text { Weighted } \\
\text { mean (SD) }\end{array}$ \\
\hline$N$ & 878 & 1775 \\
\hline General health & $47.6(7.2)$ & $N=165560.6(9.0)$ \\
\hline General vision & $68.2(7.9)$ & $6 \mathrm{I} .4(2 \mathrm{I} .4)$ \\
\hline Ocular pain & 75.1 (II.3) & $88.5(3.1)$ \\
\hline Near activities & $76.6(7.8)$ & $62.3(27.8)$ \\
\hline Distance activities & $79.2(7.5)$ & $65.6(25.1)$ \\
\hline Social functioning & $88.8(5.9)$ & $79.7(21.3)$ \\
\hline Mental health & $70.0(30.5)$ & $67.3(21.8)$ \\
\hline Role difficulties & $73.4(10.9)$ & $67.6(25.5)$ \\
\hline Dependency & $82.4(13.3)$ & $75.2(26.9)$ \\
\hline Driving & $73.1(9.1)$ & $53.7(38.2)$ \\
\hline Color vision & $91.4(3.9)$ & $83.8(14.9)$ \\
\hline Peripheral vision & $80.1(8.0)$ & $83.4(14.7)$ \\
\hline Mean composite score & $N=148275.9(8.0)$ & $N=161775.1(18.1)$ \\
\hline
\end{tabular}


Table 6 Effects of glaucoma and age-related macular degeneration (ARMD) on quality of life assessed using the Impact of Vision Impairment instrument ${ }^{9,76}$

\begin{tabular}{|c|c|c|c|c|c|c|}
\hline Study & $\mathbf{N}$ & Emotion & Leisure & Mobility & Social & Household \\
\hline \multicolumn{7}{|l|}{ Glaucoma } \\
\hline Mean score & 11 & 1.93 & 2.38 & 1.77 & 2.79 & 1.18 \\
\hline SD & & 0.98 & 1.12 & 1.04 & 1.32 & 0.49 \\
\hline \multicolumn{7}{|l|}{ ARMD } \\
\hline Mean score & 37 & 1.63 & 1.77 & 1.50 & 2.87 & 0.92 \\
\hline SD & & 0.92 & 1.04 & 0.61 & 0.76 & 0.34 \\
\hline
\end{tabular}

however the differences were clinically meaningful only with respect to ocular pain, role difficulties, driving and peripheral vision.

Three recent studies have described the burden of neovascular ARMD (NV-ARMD) on patient-reported functioning. ${ }^{10,97,98} \mathrm{NV}$-ARMD represents $10 \%$ to $15 \%$ of all ARMD and accounts for 90\% of ARMD-related severe vision loss. All three studies showed significantly lower NEI-VFQ-25 summary scores in patients with NV-ARMD compared with individuals without ARMD. ${ }^{10,97,98}$ NEI-VFQ-25 summary scores (range 48.0-52.7) were similar to those seen in the studies included in our review. In general, an association between reduced visual acuity and decreased NEI-VFQ-25 composite scores and in individual domains was observed. ${ }^{10,97,98}$ EQ-5D scores, however, were significantly lower in patients with NV-ARMD compared with controls in the largest multinational study only, ${ }^{98}$ and generally did not correlate with visual acuity. These findings support those of another study in $\mathrm{ARMD}^{99}$ and suggest that EQ-5D is not a suitable measure of QoL in this population.

\section{Choosing a QoL instrument}

When assessing vision disorders, the choice of QoL instrument should be influenced by whether comparisons with other disorders are to be made. QoL instruments are available for specific diseases; however, their utility is restricted to evaluating patients with the disease against control or reference individuals only. Unlike QoL instruments suitable for visual diseases on a more general level, they do not enable comparisons with other sight disorders.

We included vision-specific or generic instruments only in our study to allow comparisons between vision disorders. Generic instruments can be used to make comparisons across a wide range of diseases, whether vision-related or not. However, they lack the sensitivity of vision-specific QoL instruments. We found that vision-specific instruments were used more frequently than generic instruments in glaucoma and CVL diseases. The NEI-VFQ instruments were used most frequently overall, and the VF-14 questionnaire was used more often in ARMD than glaucoma. SF-36 was the most commonly used generic instrument. Although the EQ-5D is a highly useful tool for calculating health utilities that can easily be translated into health economics statistics, the lack of studies using this instrument can perhaps be explained by its poor sensitivity to the impact of loss of vision on activities of daily living. ${ }^{99}$

The authors of a recent review of the relative usefulness of QoL instruments in studying glaucoma concluded that there was not an accepted 'industry standard' tool, although they recommended NEI-VFQ instruments as a standard comparator, based mainly on their ease of use..$^{91}$ The SF-36 instrument is well validated and easy to use, but lacks correlation with visual acuity measures. ${ }^{91}$ Similarly, the SIP instrument lacks sensitivity for visual impairment; its domains are only weakly correlated with visual acuity or visual field status. ${ }^{91}$ The NEI-VFQ-51 instrument may be more sensitive than SF-36, but it takes a relatively long time to complete. The NEI-VFQ-25 instrument takes less time to complete than NEI-VFQ-51 but lacks visual field consideration compared to more specific glaucoma tools, such as the Glaucoma Quality of Life 15 scale $^{100}$ and the Symptom Impact Glaucoma Score. ${ }^{45}$ The authors of the review also suggested that some of the vision-specific instruments focus on physical rather than social or personal aspects of QoL, and therefore these latter aspects are often not fully assessed. ${ }^{91}$ As we have seen, this contrasts with the generic instruments, which show a greater impact of glaucoma on mental rather than physical aspects of QoL, and vice-versa for ARMD. A possible reason for our observations could be that, in patients with early stages of glaucoma (in whom there is minimal functional impairment), worry about blindness could affect mental QoL, while physical aspects of QoL remain relatively unaffected. 
This worry may be compounded by a lack of understanding or education about the disease, the absence of a curative treatment, and having to undergo chronic medical or surgical therapy with frequent follow-up visits as a reminder of living with a potentially blinding disorder.

\section{Study limitations}

A possible limitation of our study is that we did not search specific disease terms; the inclusion terms such as 'glaucoma' and 'ARMD' in addition to the general terms 'central vision loss' and 'peripheral vision loss' may have identified additional publications for review. However, the decision to compare glaucoma with ARMD was made following generation and analysis of the search results, once it became clear that these two diseases were the most published in terms of QoL studies in PVL and CVL, respectively. Nevertheless, the search generated a sufficient number of publications to enable us to make comparisons between peripheral and central vision loss disorders for most of the QoL instruments. Classification of the diseases into distinct CVL and PVL types presented a significant challenge. Because many disorders of the eye are difficult to differentiate as affecting peripheral rather than central vision, or vice-versa, only diseases that were considered to be more strongly associated with PVL or CVL were included. Papers that reported patients with 'visual field loss' only were not included. As already discussed, for some QoL instruments a lack of data in either glaucoma or ARMD means that some of the results should be viewed with a degree of caution.

\section{Conclusion}

Diseases associated with PVL, such as glaucoma, and CVL, such as ARMD, have a negative impact on QoL and appear to impact on different QoL domains. A greater impact on mental aspects of QoL was consistently found for PVL disorders, and on physical aspects for CVL disorders. Both disorders affected patients' expectations of treatment and their general vision. The impact of CVL has often been thought to have a greater impact on patients' QoL than PVL. We have found the impact to be comparable between PVL and CVL. As the population ages, the prevalence of vision disorders is set to rise, therefore it will become even more important to consider the impact of reduced QoL on patients, healthcare systems and society.

\section{Acknowledgments and Disclosures}

This study was funded by Allergan Inc. The authors would like to thank Natalie Barker of Wolters Kluwer Health for providing writing assistance for this manuscript (funded by Allergan Inc).

\section{References}

1. Congdon N, O'Colmain B, Klaver CC, et al. Causes and prevalence of visual impairment among adults in the United States. Arch Ophthalmol. 2004;122(4):477-485.

2. Quigley HA, Broman AT. The number of people with glaucoma worldwide in 2010 and 2020. Br J Ophthalmol. 2006;90(3):262-267.

3. Powe NR, Schein OD, Gieser SC, et al. Synthesis of the literature on visual acuity and complications following cataract extraction with intraocular lens implantation. Cataract Patient Outcome Research Team. Arch Ophthalmol. 1994;112(2):239-252.

4. Kobelt G, Lundstrom M, Stenevi U. Cost-effectiveness of cataract surgery. Method to assess cost-effectiveness using registry data. $J$ Cataract Refract Surg. 2002;28(10):1742-1749.

5. Sahel JA, Bandello F, Augustin A, Maurel F, Negrini C, Berdeaux GH. Health-related quality of life and utility in patients with age-related macular degeneration. Arch Ophthalmol. 2007;125(7):945-951.

6. Fagan S, Frech F, Pettit K, et al. Relationship between quality of life, disease severity, and physician visits in managed care patients with atopic dermatitis. Value Health. 1998;1(1):45-46.

7. Gibson PR, Weston AR, Shann A, et al. Relationship between disease severity, quality of life and health-care resource use in a cross-section of Australian patients with Crohn's disease. J Gastroenterol Hepatol. 2007;22(8):1306-1312.

8. Keranen T, Kaakkola S, Sotaniemi K, et al. Economic burden and quality of life impairment increase with severity of PD. Parkinsonism Relat Disord. 2003;9(3):163-168.

9. Livingston G, Katona C, Roch B, Guilhaume C, Rive B. A dependency model for patients with Alzheimer's disease: its validation and relationship to the costs of care - the LASER-AD Study. Curr Med Res Opin. 2004;20(7):1007-1016.

10. Lotery A, Xu X, Zlatava G, Loftus J. Burden of illness, visual impairment and health resource utilisation of patients with neovascular age-related macular degeneration: results from the UK cohort of a five-country cross-sectional study. $B r J$ Ophthalmol. 2007;91(10): 1303-1307.

11. Mangione CM, Lee PP, Pitts J, Gutierrez P, Berry S, Hays RD. Psychometric properties of the National Eye Institute Visual Function Questionnaire (NEI-VFQ). NEI-VFQ Field Test Investigators. Arch Ophthalmol. 1998;116(11):1496-1504.

12. Parrish RK, 2nd. Visual impairment, visual functioning, and quality of life assessments in patients with glaucoma. Trans Am Ophthalmol Soc. 1996;94:919-1028.

13. Parrish RK 2nd, Gedde SJ, Scott IU, et al. Visual function and quality of life among patients with glaucoma. Arch Ophthalmol. 1997;115(11):1447-1455.

14. Scott IU, Smiddy WE, Schiffman J, Feuer WJ, Pappas CJ. Quality of life of low-vision patients and the impact of low-vision services. Am J Ophthalmol. 1999;128(1):54-62.

15. Ware JE Jr, Sherbourne CD. The MOS 36-item short-form health survey (SF-36). I. Conceptual framework and item selection. Med Care. 1992;30(6):473-483.

16. Ware J Jr, Kosinski M, Keller SD. A 12-Item Short-Form Health Survey: construction of scales and preliminary tests of reliability and validity. Med Care. 1996;34(3):220-233.

17. The EuroQol Group. EuroQol - a new facility for the measurement of health-related quality of life. Health Policy. 1990;16(3):199-208.

18. Gilson BS, Gilson JS, Bergner M, et al. The sickness impact profile. Development of an outcome measure of health care. Am J Public Health. 1975;65(12):1304-1310.

19. Carter WB, Bobbitt RA, Bergner M, Gilson BS. Validation of an interval scaling: the sickness impact profile. Health Serv Res. 1976;11(4): 516-528. 
20. Bergner M, Bobbitt RA, Kressel S, Pollard WE, Gilson BS, Morris JR. The sickness impact profile: conceptual formulation and methodology for the development of a health status measure. Int $J$ Health Serv. 1976;6(3):393-415.

21. Bergner M, Bobbitt RA, Pollard WE, Martin DP, Gilson BS. The sickness impact profile: validation of a health status measure. Med Care. 1976;14(1):57-67.

22. Mangione CM, Lee PP, Gutierrez PR, Spritzer K, Berry S, Hays RD. Development of the 25-item National Eye Institute Visual Function Questionnaire. Arch Ophthalmol. 2001;119(7):1050-1058.

23. Mangione CM, Berry S, Spritzer K, et al. Identifying the content area for the 51-item National Eye Institute Visual Function Questionnaire: results from focus groups with visually impaired persons. Arch Ophthalmol. 1998;116(2):227-233.

24. Weih LM, Hassell JB, Keeffe J. Assessment of the impact of vision impairment. Invest Ophthalmol Vis Sci. 2002;43(4):927-935.

25. Steinberg EP, Tielsch JM, Schein OD, et al. The VF-14. An index of functional impairment in patients with cataract. Arch Ophthalmol. 1994;112(5):630-638

26. Mackenzie PJ, Chang TS, Scott IU, et al. Assessment of visionrelated function in patients with age-related macular degeneration. Ophthalmology. 2002;109(4):720-729.

27. Mangione CM, Gutierrez PR, Lowe G, Orav EJ, Seddon JM. Influence of age-related maculopathy on visual functioning and health-related quality of life. Am J Ophthalmol. 1999;128(1):45-53.

28. Pham TQ, Cugati S, Rochtchina E, Mitchell P, Maloof A, Wang JJ. Age-related maculopathy and cataract surgery outcomes: visual acuity and health-related quality of life. Eye. 2007;21(3) 324-330.

29. Reeves BC, Harper RA, Russell WB. Enhanced low vision rehabilitation for people with age related macular degeneration: a randomised controlled trial. Br J Ophthalmol. 2004;88(11):1443-1449.

30. Chia EM, Mitchell P, Rochtchina E, Foran S, Wang JJ. Unilateral visual impairment and health related quality of life: the Blue Mountains Eye Study. Br J Ophthalmol. 2003;87(4):392-395.

31. Chia EM, Wang JJ, Rochtchina E, Smith W, Cumming RR, Mitchell P. Impact of bilateral visual impairment on health-related quality of life: the Blue Mountains Eye Study. Invest Ophthalmol Vis Sci. 2004;45(1) 71-76.

32. Lee JE, Fos PJ, Zuniga MA, Kastl PR, Sung JH. Health-related quality of life of cataract patients: cross-cultural comparisons of utility and psychometric measures. Ophthalmic Epidemiol. 2003;10(3): 177-191.

33. Hawkins BS, Miskala PH, Bass EB, et al. Surgical removal vs observation for subfoveal choroidal neovascularization, either associated with the ocular histoplasmosis syndrome or idiopathic: II. Quality of life findings from a randomized clinical trial: SST Group H Trial: SST Report No. 10. Arch Ophthalmol. 2004;122(11): 1616-1628.

34. Tranos PG, Ghazi-Nouri SM, Rubin GS, Adams ZC, Charteris DG. Visual function and subjective perception of visual ability after macular hole surgery. Am J Ophthalmol. 2004;138(6):995-1002.

35. Musch DC, Farjo AA, Meyer RF, Waldo MN, Janz NK. Assessment of health-related quality of life after corneal transplantation. Am J Ophthalmol. 1997;124(1):1-8.

36. Gordon MO, Kass MA. The Ocular Hypertension Treatment Study: design and baseline description of the participants. Arch Ophthalmol. 1999;117(5):573-583.

37. Cahill MT, Banks AD, Stinnett SS, Toth CA. Vision-related quality of life in patients with bilateral severe age-related macular degeneration. Ophthalmology. 2005;112(1):152-158.

38. Cahill MT, Stinnett SS, Banks AD, Freedman SF, Toth CA. Quality of life after macular translocation with 360 degrees peripheral retinectomy for age-related macular degeneration. Ophthalmology. 2005;112(1):144-151.

39. Hassell JB, Lamoureux EL, Keeffe JE. Impact of age related macular degeneration on quality of life. Br J Ophthalmol. 2006;90(5):593-596.
40. Lamoureux EL, Hassell JB, Keeffe JE. The determinants of participation in activities of daily living in people with impaired vision. Am J Ophthalmol. 2004;137(2):265-270.

41. Espindle D, Crawford B, Maxwell A, et al. Quality of life improvements in cataract patients with bilateral blue light-filtering intraocular lenses: clinical trial. J Cataract Refract Surg. 2005;31(10):1952-1959.

42. Kobelt G, Jonsson B, Bergstrom A, Chen E, Linden C, Alm A. Cost-effectiveness analysis in glaucoma: what drives utility? Results from a pilot study in Sweden. Acta Ophthalmol Scand. 2006;84(3): 363-371.

43. Conner-Spady BL, Sanmugasunderam S, Courtright P, McGurran JJ, Noseworthy TW. Determinants of patient satisfaction with cataract surgery and length of time on the waiting list. Br J Ophthalmol. 2004;88(10):1305-1309.

44. Kompella VB, Sangwan VS, Bansal AK, Garg P, Aasuri MK, Rao GN. Ophthalmic complications and management of Stevens-Johnson syndrome at a tertiary eye care centre in south India. Indian J Ophthalmol. 2002;50(4):283-286.

45. Janz NK, Wren PA, Lichter PR, Musch DC, Gillespie BW, Guire KE. Quality of life in newly diagnosed glaucoma patients: The Collaborative Initial Glaucoma Treatment Study. Ophthalmology. 2001;108(5):887-897; discussion 898

46. Janz NK, Wren PA, Lichter PR, et al. The Collaborative Initial Glaucoma Treatment Study: interim quality of life findings after initial medical or surgical treatment of glaucoma. Ophthalmology. 2001;108(11):1954-1965.

47. Desai P, Reidy A, Minassian DC, Vafidis G, Bolger J. Gains from cataract surgery: visual function and quality of life. Br J Ophthalmol. 1996;80(10):868-873

48. Steinberg EP, Tielsch JM, Schein OD, et al. National study of cataract surgery outcomes. Variation in 4-month postoperative outcomes as reflected in multiple outcome measures. Ophthalmology. 1994;101(6):1131-1140; discussion 1140-1131.

49. Cole SR, Beck RW, Moke PS, Gal RL, Long DT. The National Eye Institute Visual Function Questionnaire: experience of the ONTT. Optic Neuritis Treatment Trial. Invest Ophthalmol Vis Sci. 2000;41(5):1017-1021.

50. Tranos PG, Topouzis F, Stangos NT, et al. Effect of laser photocoagulation treatment for diabetic macular oedema on patient's vision-related quality of life. Curr Eye Res. 2004;29(1):41-49.

51. Baker RS, Bazargan M, Calderon JL, Hays RD. Psychometric performance of the National Eye Institute visual function questionnaire in Latinos and non-Latinos. Ophthalmology. 2006;113(8):1363-1371.

52. Berdeaux GH, Nordmann JP, Colin E, Arnould B. Vision-related quality of life in patients suffering from age-related macular degeneration. Am J Ophthalmol. 2005;139(2):271-279.

53. Clemons TE, Chew EY, Bressler SB, McBee W. National Eye Institute Visual Function Questionnaire in the Age-Related Eye Disease Study (AREDS): AREDS Report No. 10. Arch Ophthalmol. 2003;121(2):211-217.

54. Lindblad AS, Clemons TE. Responsiveness of the National Eye Institute Visual Function Questionnaire to progression to advanced age-related macular degeneration, vision loss, and lens opacity: AREDS Report no. 14. Arch Ophthalmol. 2005;123(9):1207-1214.

55. Gedde SJ, Schiffman JC, Feuer WJ, Parrish RK, 2nd, Heuer DK, Brandt JD. The tube versus trabeculectomy study: design and baseline characteristics of study patients. Am J Ophthalmol. 2005;140(2): 275-287.

56. Hyman LG, Komaroff E, Heijl A, Bengtsson B, Leske MC. Treatment and vision-related quality of life in the early manifest glaucoma trial. Ophthalmology. 2005;112(9):1505-1513.

57. Jampel HD. Glaucoma patients' assessment of their visual function and quality of life. Trans Am Ophthalmol Soc. 2001;99:301-317.

58. Jampel HD, Friedman DS, Quigley H, Miller R. Correlation of the binocular visual field with patient assessment of vision. Invest Ophthalmol Vis Sci. 2002;43(4):1059-1067.

59. Jampel HD, Schwartz A, Pollack I, Abrams D, Weiss H, Miller R. Glaucoma patients' assessment of their visual function and quality of life. J Glaucoma. 2002;11(2):154-163. 
60. Nordmann JP, Viala M, Sullivan K, Arnould B, Berdeaux G. Psychometric Validation of the National Eye Institute Visual Function Questionnaire-25 (NEI VFQ-25) French version: in a population of patients treated for ocular hypertension and glaucoma. Pharmacoeconomics. 2004;22(3):197-206.

61. Suzukamo Y, Oshika T, Yuzawa M, et al. Psychometric properties of the 25-item National Eye Institute Visual Function Questionnaire (NEI VFQ-25), Japanese version. Health Qual Life Outcomes. 2005;3:65.

62. Brody BL, Roch-Levecq AC, Gamst AC, Maclean K, Kaplan RM, Brown SI. Self-management of age-related macular degeneration and quality of life: a randomized controlled trial. Arch Ophthalmol. 2002;120(11):1477-1483

63. DeCarlo DK, Scilley K, Wells J, Owsley C. Driving habits and healthrelated quality of life in patients with age-related maculopathy. Optom Vis Sci. 2003;80(3):207-213.

64. Hudson HL, Lane SS, Heier JS, et al. Implantable miniature telescope for the treatment of visual acuity loss resulting from end-stage age-related macular degeneration: 1-year results. Ophthalmology. 2006;113(11):1987-2001.

65. Maguire M. Baseline characteristics, the 25-Item National Eye Institute Visual Functioning Questionnaire, and their associations in the Complications of Age-Related Macular Degeneration Prevention Trial (CAPT). Ophthalmology. 2004;111(7):1307-1316.

66. Scilley K, DeCarlo DK, Wells J, Owsley C. Vision-specific healthrelated quality of life in age-related maculopathy patients presenting for low vision services. Ophthalmic Epidemiol. 2004;11(2):131-146.

67. Williams GP, Pathak-Ray V, Austin MW, Lloyd AP, Millington IM, Bennett A. Quality of life and visual rehabilitation: an observational study of low vision in three general practices in West Glamorgan. Eye. 2007;21(4):522-527.

68. Miskala PH, Hawkins BS, Mangione CM, et al. Responsiveness of the National Eye Institute Visual Function Questionnaire to changes in visual acuity: findings in patients with subfoveal choroidal neovascularization-SST Report No. 1. Arch Ophthalmol. 2003;121(4): 531-539.

69. Dong LM, Childs AL, Mangione CM, et al. Health- and vision-related quality of life among patients with choroidal neovascularization secondary to age-related macular degeneration at enrollment in randomized trials of submacular surgery: SST report no. 4. Am J Ophthalmol. 2004;138(1):91-108.

70. Submacular Surgery Trials Research Group. Health- and vision-related quality of life among patients with ocular histoplasmosis or idiopathic choroidal neovascularization at enrollment in a randomized trial of submacular surgery: Submacular Surgery Trials Report No. 5. Arch Ophthalmol. 2005;123(1):78-88.

71. Deramo VA, Cox TA, Syed AB, Lee PP, Fekrat S. Vision-related quality of life in people with central retinal vein occlusion using the 25-item National Eye Institute Visual Function Questionnaire. Arch Ophthalmol. 2003;121(9):1297-1302.

72. Hirneiss C, Neubauer AS, Gass CA, et al. Visual quality of life after macular hole surgery: outcome and predictive factors. Br JOphthalmol. 2007;91(4):481-484.

73. Beck RW, Gal RL, Bhatti MT, et al. Visual function more than 10 years after optic neuritis: experience of the optic neuritis treatment trial. Am J Ophthalmol. 2004;137(1):77-83.

74. Kymes SM, Walline JJ, Zadnik K, Gordon MO. Quality of life in keratoconus. Am J Ophthalmol. 2004;138(4):527-535.

75. Walline JJ, Bailey MD, Zadnik K. Vision-specific quality of life and modes of refractive error correction. Optom Vis Sci. 2000;77(12): $648-652$.

76. Keeffe JE, McCarty CA, Hassell JB, Gilbert AG. Description and measurement of handicap caused by vision impairment. Aust $N Z \mathrm{~J}$ Ophthalmol. 1999;27(3-4):184-186.

77. Armbrecht AM, Aspinall PA, Dhillon B. A prospective study of visual function and quality of life following PDT in patients with wet age related macular degeneration. Br J Ophthalmol. 2004;88(10): $1270-1273$.
78. Armbrecht AM, Findlay C, Aspinall PA, Hill AR, Dhillon B. Cataract surgery in patients with age-related macular degeneration: one-year outcomes. J Cataract Refract Surg. 2003;29(4):686-693.

79. Armbrecht AM, Findlay C, Kaushal S, Aspinall P, Hill AR, Dhillon B. Is cataract surgery justified in patients with age related macular degeneration? A visual function and quality of life assessment. $\mathrm{Br} J$ Ophthalmol. 2000;84(12):1343-1348.

80. Bansback N, Czoski-Murray C, Carlton J, et al. Determinants of health related quality of life and health state utility in patients with age related macular degeneration: the association of contrast sensitivity and visual acuity. Qual Life Res. 2007;16(3):533-543.

81. Hewitt AW, Jeganathan VS, Kidd JE, Pesudovs K, Verma N. Influence of photodynamic therapy for age related macular degeneration upon subjective vision related quality of life. Graefes Arch Clin Exp Ophthalmol. 2006;244(8):972-977.

82. Riusala A, Sarna S, Immonen I. Visual function index (VF-14) in exudative age-related macular degeneration of long duration. Am J Ophthalmol. 2003;135(2):206-212.

83. Boisjoly H, Gresset J, Charest M, et al. The VF-14 index of visual function in recipients of a corneal graft: a 2-year follow-up study. Am J Ophthalmol. 2002;134(2):166-171.

84. Javitt JC, Steinberg EP, Sharkey P, et al. Cataract surgery in one eye or both. A billion dollar per year issue. Ophthalmology. 1995;102(11):1583-1592; discussion 1592-1583.

85. Kafil-Hussain N, Khooshebah R. Clinical research, comparison of the subjective visual function in patients with epiphora and patients with second-eye cataract. Orbit. 2005;24(1):33-38.

86. Lundqvist B, Monestam E. Longitudinal changes in subjective and objective visual function 5 years after cataract surgery Prospective population-based study. J Cataract Refract Surg. 2006;32(11): 1944-1950.

87. Pager CK. Assessment of visual satisfaction and function after cataract surgery. J Cataract Refract Surg. 2004;30(12):2510-2516.

88. Rosen PN, Kaplan RM, David K. Measuring outcomes of cataract surgery using the Quality of Well-Being Scale and VF-14 Visual Function Index. J Cataract Refract Surg. 2005;31(2):369-378.

89. Valderas JM, Rue M, Guyatt G, Alonso J. The impact of the VF-14 index, a perceived visual function measure, in the routine management of cataract patients. Qual Life Res. 2005;14(7):1743-1753.

90. Esteban JJ, Martinez MS, Navalon PG, et al. Visual impairment and quality of life: gender differences in the elderly in Cuenca, Spain. Qual Life Res. 2008;17(1):37-45.

91. Severn P, Fraser S, Finch T, May C. Which quality of life score is best for glaucoma patients and why? BMC Ophthalmol. 2008;8:2.

92. Broman AT, Munoz B, Rodriguez J, et al. The impact of visual impairment and eye disease on vision-related quality of life in a Mexican-American population: proyecto VER. Invest Ophthalmol Vis Sci. 2002;43(11):3393-3398.

93. Hahm BJ, Shin YW, Shim EJ, et al. Depression and the vision-related quality of life in patients with retinitis pigmentosa. $\mathrm{Br} J$ Ophthalmol. 2008;92(5):650-654

94. Papageorgiou E, Hardiess G, Schaeffel F, et al. Assessment of visionrelated quality of life in patients with homonymous visual field defects. Graefes Arch Clin Exp Ophthalmol. 2007;245(12):1749-1758.

95. Gall C, Mueller I, Gudlin J, et al. Vision- and health-related quality of life before and after vision restoration training in cerebrally damaged patients. Restor Neurol Neurosci. 2008;26(4-5):341-353.

96. Gall C, Lucklum J, Sabel BA, Franke GH. Vision- and health-related quality of life in patients with visual field loss after postchiasmatic lesions. Invest Ophthalmol Vis Sci. 2009;50(6):2765-2776.

97. Cruess A, Zlateva G, Xu X, Rochon S. Burden of illness of neovascular age-related macular degeneration in Canada. Canadian Journal of Ophthalmology. 2007;42(6):836-843.

98. Soubrane G, Cruess A, Lotery A, et al. Burden and health care resource utilization in neovascular age-related macular degeneration: findings of a multicountry study.[see comment]. Archives of Ophthalmology. 2007;125(9):1249-1254. 
99. Espallargues M, Czoski-Murray CJ, Bansback NJ, et al. The impact of age-related macular degeneration on health status utility values. Invest Ophthalmol Vis Sci. 2005;46(11):4016-4023.
100. Nelson P, Aspinall P, Papasouliotis O, Worton B, O’Brien C. Quality of life in glaucoma and its relationship with visual function. J Glaucoma. 2003;12(2):139-150.

\section{Publish your work in this journal}

Clinical Ophthalmology is an international, peer-reviewed journal covering all subspecialties within ophthalmology. Key topics include: Optometry; Visual science; Pharmacology and drug therapy in eye diseases; Basic Sciences; Primary and Secondary eye care; Patient Safety and Quality of Care Improvements. This journal is indexed on

Submit your manuscript here: http://www.dovepress.com/clinical-ophthalmology-journal

\section{Dovepress}

PubMed Central and CAS, and is the official journal of The Society of Clinical Ophthalmology (SCO). The manuscript management system is completely online and includes a very quick and fair peer-review system, which is all easy to use. Visit http://www.dovepress.com/ testimonials.php to read real quotes from published authors. 